\title{
Association between metabolic syndrome components and
}

\section{the risk of developing nephrolithiasis: A systematic review}

\section{and bayesian meta-analysis [version 1; peer review: 2}

\section{approved]}

\author{
Ilham Akbar Rahman (iD1, Ilham Fauzan Nusaly1, Syakri Syahrir², Harry Nusaly², \\ Makbul Aman Mansyur ${ }^{3}$
}

${ }^{1}$ Faculty of Medicine, Hasanuddin University, Makassar, South Sulawesi, 90222, Indonesia

2Department of Urology, Faculty of Medicine, Hasanuddin University, Makassar, South Sulawesi, 90245, Indonesia

${ }^{3}$ Department of Internal Medicine, Faculty of Medicine, Hasanuddin University, Makassar, South Sulawesi, 90245, Indonesia

V1 First published: 11 Feb 2021, 10:104

https://doi.org/10.12688/f1000research.28346.1

Latest published: 11 Feb 2021, 10:104

https://doi.org/10.12688/f1000research.28346.1

\section{Abstract}

Background: There is increasing evidence that nephrolithiasis is a systemic disease, as opposed to an isolated urinary metabolic problem, after considerable links were found between nephrolithiasis and systemic diseases such as hypertension, obesity, dyslipidemia, and insulin resistance. The interplay between these four factors defines metabolic syndrome (MetS). In this review we aim to clarify the associations of MetS and its components to kidney stone incident. Methods: Online databases of EMBASE, MEDLINE, and Google Scholar were searched from January 1998 up to October 2020 to identify observational studies examining the association between metabolic syndrome components and kidney stone incident. Bayesian randomeffects meta-analysis and meta-regression were performed to observe the association. Linear dose-response analysis was conducted to shape the direction of the association. Data analysis was performed using STATA, and R statistics.

Results: A total of 25 potentially relevant studies ( $n=934,588$ participants) were eventually identified. The pooled results suggested that metabolic syndrome was associated with an increased risk of nephrolithiasis with an odds ratio (OR) of 1.769 (95\% CI: 1.386 2.309). The summary OR of hypertension and dyslipidemia for developing nephrolithiasis were 1.613 (95\% CI: $1.213-2.169)$ and 1.586 (95\% CI: 1.007 - 2.502) respectively. The presence of diabetes mellitus and obesity had an OR of 1.552 (95\% CI: $1.027-2.344)$ and 1.531 (95\% CI: $1.099-2.109$ ) respectively. Our results revealed that the increasing number of MetS traits will increase the risk of developing nephrolithiasis, the higher the fasting plasma glucose, and

\section{Open Peer Review \\ Approval Status \\ 1 \\ version 1 \\ 11 Feb 2021

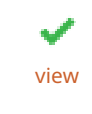 \\ 2 \\ 1. Joseph philipraj, Mahatma Gandhi Medical College and Research Institute, \\ Pillayarkuppam, India \\ Vishnuvardhan Rudravaram, Pondicherry \\ university, Kalapet, India \\ 2. Muhammad Faruk iD, Hasanuddin \\ University, Makassar, Indonesia \\ Any reports and responses or comments on the article can be found at the end of the article.}


body mass index, the higher the risk of kidney stones incident.

Conclusions: Our results suggest that hypertension, diabetes, obesity

and dyslipidemia are associated with increased risk of developing

nephrolithiasis. Linear significant association between MetS

components and nephrolithiasis were revealed in our study which

reinforced the notion that should be considered a systemic disorder.

Keywords

Metabolic syndrome, Hypertension, Obesity, Dyslipidemia, Diabetes,

Nephrolithiasis

Corresponding author: Ilham Akbar Rahman (ilhamakbaarr@gmail.com)

Author roles: Rahman IA: Conceptualization, Data Curation, Investigation, Methodology, Software, Writing - Original Draft Preparation, Writing - Review \& Editing; Nusaly IF: Investigation, Writing - Original Draft Preparation; Syahrir S: Supervision, Validation, Writing -

Review \& Editing; Nusaly H: Supervision, Validation, Writing - Review \& Editing; Mansyur MA: Formal Analysis, Supervision, Validation,

Writing - Review \& Editing

Competing interests: No competing interests were disclosed.

Grant information: The author(s) declared that no grants were involved in supporting this work.

Copyright: $\odot 2021$ Rahman IA et al. This is an open access article distributed under the terms of the Creative Commons Attribution License, which permits unrestricted use, distribution, and reproduction in any medium, provided the original work is properly cited.

How to cite this article: Rahman IA, Nusaly IF, Syahrir S et al. Association between metabolic syndrome components and the risk of developing nephrolithiasis: A systematic review and bayesian meta-analysis [version 1; peer review: 2 approved] F1000Research 2021, 10:104 https://doi.org/10.12688/f1000research.28346.1

First published: 11 Feb 2021, 10:104 https://doi.org/10.12688/f1000research.28346.1 


\section{Introduction}

Kidney stone disorder, characterized by abnormal urine composition and dehydration, is an increasingly common condition that is most common in older men (Shoag et al., 2015). Its incidence and occurrence has grown progressively and globally for decades. It has been reported that nephrolithiasis was found in all ages, peaking between the ages of 20 and 60 where it rapidly increases between the ages of 40 to 59 (Hiatt et al., 1982).

In recent years, nephrolithiasis is hypothesized to be a systemic disorder which requires more attention and evaluation in primary health care. The prevalence of kidney stones has increased and been associated with the components of metabolic syndrome including obesity, elevated blood pressure, dyslipidemia, and glucose intolerance (Obligado \& Goldfarb, 2008; Sakhaee, 2008; Sakhaee, 2009; Sakhaee \& Maalouf, 2008). As opposed to an isolated urinary metabolic problem, research showed that it was related to an increased risk of several comorbidities such as coronary heart disease, stroke, renal cell carcinoma and end-stage renal disease (ESRD) (Dhondup et al., 2018; Peng \& Zheng, 2017; van de Pol et al., 2019). In addition to being a prevalent and costly problem, recent evidence also showed that urinary stones are associated with several metabolic traits such as hypertension, diabetes mellitus (DM), and obesity (Kovshilovskaya et al., 2012; West et al., 2008). Comprehensive evidence shows that the association seems to be reciprocal: either stone formers seem to induce MetS or ones with MetS induce the increasing risk of kidney stones (Reiner et al., 2011). Several meta-analyses have found an association between hypertension and diabetes mellitus in nephrolithiasis patients (Aune et al., 2018; Shang et al., 2017). However, there are no previous studies that have compared all possible metabolic syndrome traits in determining which traits have the most significant influence for the risk of nephrolithiasis and to determine the direction of the association. Moreover, due to sample size problems individual studies may not have enough - statistical power, therefore we performed a systematic review and meta-analysis to determine the association between all possible metabolic syndrome traits to assess the most significant risk for developing nephrolithiasis from all the evidence. Meta-regression and dose response analysis were performed to assess the direction of association. All these analyses were implemented in a Bayesian framework so that we could provide the results with more confidence (O'Hagan, 2004; Spiegelhalter, 2004). Our study outcome could clarify the association between metabolic syndrome and its components to the risk of developing nephrolithiasis.

\section{Methods}

Literature search strategy and literature selection

Relevant articles were retrieved from online databases including EMBASE, MEDLINE and Google scholar from January 1998 until October 2020. The search strategy consisted of two parts (metabolic syndrome and nephrolithiasis) using specific keywords combined with medical subject heading (MeSH) terms and words: "metabolic syndrome ", "hypertension", "diabetes mellitus", "insulin resistance", "dyslipidemia", "obesity”, "waistcircumferences", "hypertriacylglycerolemia", "hypertriglyceridemia", "kidney stones", "nephrolithiasis". The full texts and abstracts were originally and independently selected by two reviewers. Full texts and abstracts were scored accordingto the inclusion and exclusion criteria. The studies which did not fit with the inclusion criteria were excluded. Discrepancies between the two reviewers were resolved through a discussion with a third reviewer. Ethical approval was not required because the data did not contain individual patient information.

\section{Data extraction and quality assessment}

The studies included in this article met the following criteria: (1) the subjects were nephrolithiasis patients; (2) research was conducted as observational study to show causal-effect relationship (case control or cohort studies); (3) the study showed association as risk with $95 \% \mathrm{CI}$; (4) the language of the article was published in English. Two reviewers (IAR and IF) separately extracted and analyzed the data based on study selection criteria using standardized, structured and pilot extraction forms. The results were reviewed and discussed by IAR and IF to complete the included studies. Any discrepancies were resolved in a discussion with a third reviewer. For each included study, several pieces of information were extracted including author name, year of publication, number of sample sizes, mean age, study design, countries, number of participants and cases, study period, predictors and outcomes. Table 1 comprehensively shows all of the above data. Newcastle Ottawa Scale (NOS) tool was used to assess the relevance of the included studies and the strength of the evidence. Figure 1 shows the detailed literature search and selection process as PRISMA guideline was followed. Publication bias was investigated by the Begg and Egger tests.

\section{Outcome}

Primary endpoint was the occurrence of kidney stones with the predictors assessed as metabolic syndrome traits. Secondary endpoint was the direction of association assessing between the dose of the predictors and the response of kidney stones occurrence.

\section{Statistical analysis}

We performed an empirical Bayesian random effect metaanalysis and meta regression to understand the association between predictors and outcome of kidney stones. All data were analyzed using R language (version 1.2.1335), STATA (version 12.0; Stata Corp LP, College Station, TX) and R. An odds ratio (OR) with a 95\% confidence interval (CI) used for each association was generated using Bayesian meta-analysis. The comparison of risk factors with each other was conducted based on OR, where HRs (Hazard Ratio) and RRs (Risk Ratio) were both directly considered as OR (Greenland, 1987), for kidney stones outcome by performing the simulation with 16,000 iterations and with the burned out of 10,000 iterations in the Bayesian meta-analysis model. Chi-squared based on Q-statistic test $(\mathrm{P}<0.10)$ and $\mathrm{I}^{2}$ statistic quantification were used to assess heterogeneity of studies. $\mathrm{I}^{2}$ values of heterogeneity were 
Table 1. Baseline characteristics of included studies.

\begin{tabular}{|c|c|c|c|c|c|}
\hline Author, year & Metaboli Syndrome Traits & Study design & $\begin{array}{l}\text { Mean } \\
\text { Age }\end{array}$ & Country & $\begin{array}{l}\text { Study } \\
\text { Population }\end{array}$ \\
\hline Sandra L. Ramsey, 2004 & Hypertension & $\begin{array}{l}\text { Cross-sectional } \\
\text { study }\end{array}$ & 37 & US & 2818 \\
\hline Francois Madore, 1998 & Hypertension & $\begin{array}{l}\text { Prospective cohort } \\
\text { study }\end{array}$ & 54 & US & 47418 \\
\hline Yen-Tze Liu, 2017 & $\begin{array}{l}\text { Hypertension, Low HDL, Obesity, } \\
\text { Metabolic Syndrome }\end{array}$ & $\begin{array}{l}\text { Cross-sectional } \\
\text { study }\end{array}$ & 46 & Taiwan & 3886 \\
\hline Francesco P. Cappuccio, 1999 & Hypertension & $\begin{array}{l}\text { Prospective cohort } \\
\text { study }\end{array}$ & 46.5 & Italy & 503 \\
\hline Massimmo Cirillo, 1988 & Hypertension & $\begin{array}{l}\text { Cross-sectional } \\
\text { study }\end{array}$ & NA & Italy & 5376 \\
\hline Sheng-Han Tsai, 2018 & $\begin{array}{l}\text { Hypertension, Obesity, DM, } \\
\text { Dislipidemia }\end{array}$ & $\begin{array}{l}\text { Retrospective } \\
\text { cohort study }\end{array}$ & 43.3 & Taiwan & 39124 \\
\hline In Gab Jeong, 2011 & $\begin{array}{l}\text { Hypertension, Obesity, DM, Low } \\
\text { HDL, Metabolic Syndrome }\end{array}$ & Cohort retrospective & 50 & Korea & 34895 \\
\hline Hao Ping, 2019 & Hypertension, Obesity, DM & Cohort prospective & 46.23 & China & 9667 \\
\hline Xiang Shu, 2017 & Hypertension, Obesity & Cohort prospective & 52 & China & 127220 \\
\hline Loris Borghi, 1999 & Hypertension & Cohort prospective & 42 & Italy & 267 \\
\hline Saloua Akoudad, 2010 & Hypertension & Cohort prospective & 60 & US & 12161 \\
\hline Elichi Yoshimura, 2015 & Obesity & Cohort prospective & 31 & Japan & 4074 \\
\hline Eiji Oda, 2014 & Obesity & Cohort retrospective & 51 & Japan & 2718 \\
\hline Mathew D. Sorensen, 2014 & Obesity & Cohort prospective & 63.5 & US & 84225 \\
\hline Eric N. Taylor, 2005 & Diabetes Mellitus & Cohort prospective & 47 & US & 220478 \\
\hline Mu Tsun Shih, 2016 & $\begin{array}{l}\text { Hypertension, Diabetes Mellitus, } \\
\text { Dyslipidemia }\end{array}$ & Cohort retrospective & 44 & Taiwan & 3344 \\
\hline James H. Masterson, 2015 & Diabetes Mellitus, Dyslipidemia & Cohort retrospective & 31 & US & 52184 \\
\hline Qi Ding, 2018 & Dyslipidemia & Case control study & 55 & China & 1196 \\
\hline Domenico Rendina, 2009 & Low HDL & Cohort prospective & 63 & Italy & 2132 \\
\hline Ho Won Kang, 2014 & Low HDL & Cohort retrospective & 47 & Korea & 2620 \\
\hline In Ho Chang, 2011 & Metabolic Syndrome & Cohort prospective & 42 & Korea & 3872 \\
\hline Yang-Ju Kim, 2013 & Metabolic Syndrome & Cohort retrospective & 45 & Korea & 116536 \\
\hline Yasuo Kohjimoto, 2013 & Metabolic Syndrome & $\begin{array}{l}\text { Cross-sectional } \\
\text { study }\end{array}$ & 52 & Japan & 11555 \\
\hline Bradford West, 2008 & Metabolic Syndrome & $\begin{array}{l}\text { Cross-sectional } \\
\text { study }\end{array}$ & 52 & US & 14870 \\
\hline A. J. Landgren, 2017 & Hypertension, Obesity & Cohort prospective & 69 & Sweden & 131449 \\
\hline
\end{tabular}




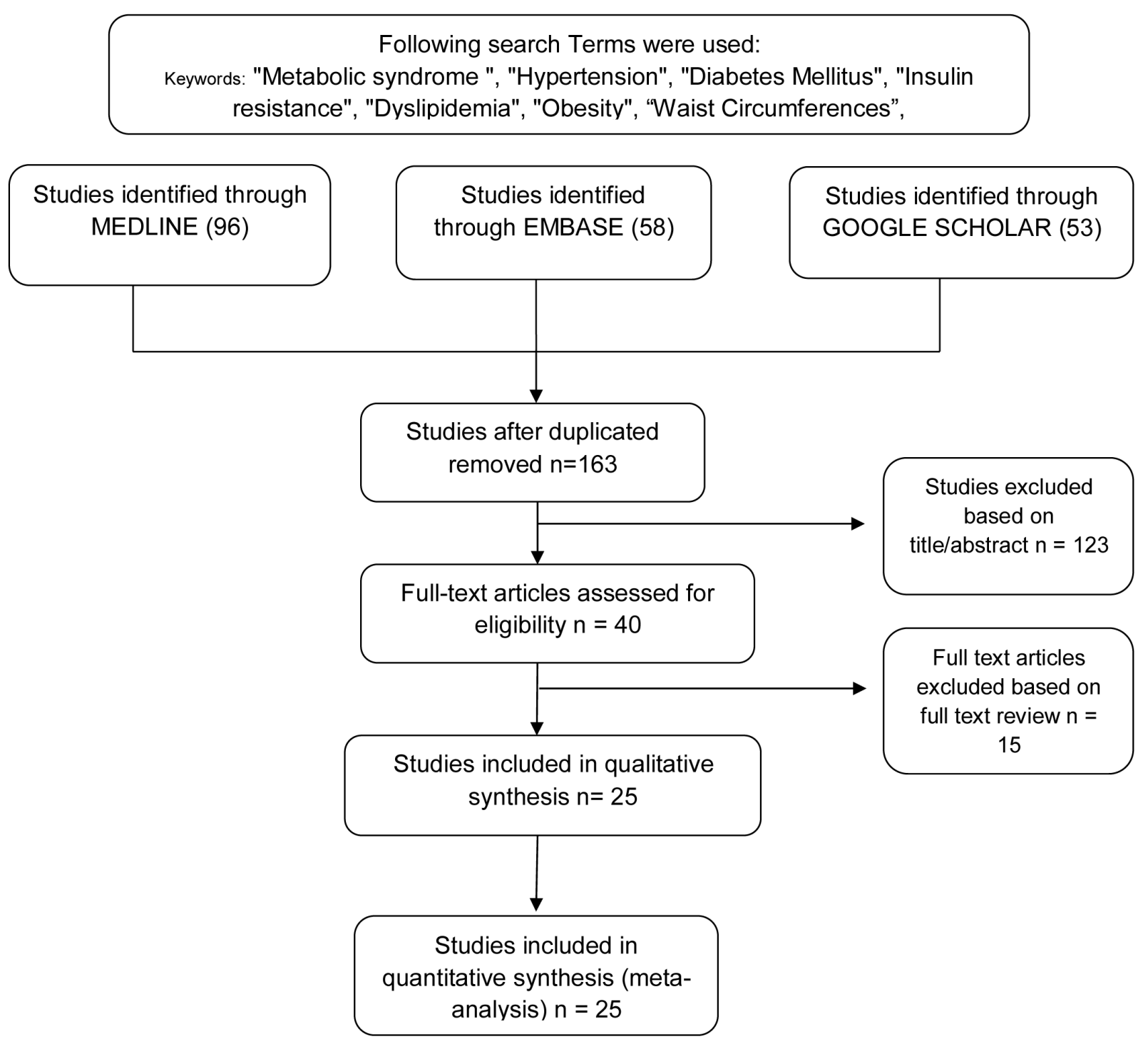

Figure 1. Flowchart of systematic literature identification and selection process implementing Preferred Reporting Items for Systematic Reviews and Meta-Analyses guide.

interpreted as insignificant (0-25\%), low (26-50\%), moderate $(51-75 \%)$ and high (>75\%) (Higgins et al., 2003). Empirical Bayesian random effects meta-regression was further conducted to explore the impact of moderators in the study effect size. Linear dose response analysis was conducted to shape the direction of association. Sensitivity analyses were conducted to explore various levels of heterogeneity between studies and observe how the results will change for different values of between study variance $\tau^{2}$ and the heterogeneity statistic $I^{2}$. Publication bias and small study effect were evaluated by funnel plots, Egger's regression test and Begg's rank correlation test.

\section{Results}

Search results and included strategies

This meta-analysis study included a total of 207 studies found using the search strategy. A full text review and abstract selection were then performed and 138 studies were excluded due to reviews, case reports, duplicates, and not in English. Finally, 25 
studies met the inclusion criteria of 934,588 patients, which were eligible and added for further analysis. A block diagram of the procedure for searching and selecting studies is shown in Figure 1.

\section{Relationships between metabolic syndrome and nephrolithiasis}

As demonstrated in Figure 2, prior metabolic syndrome was significantly associated with the mean risk of nephrolithiasis (OR: 1.769 ; 95\% CI, 1.386-2.309) in the meta-analysis of 6 studies. There was low heterogeneity ( $\mathrm{Q}$ test; $\mathrm{I} 2=66.84 \%$ ). Also, publication bias and small study effect were not found based on the symmetry of the funnel plot (Supplementary material 1a (Rahman et al., 2021b)) and the Begg's rank correlation test $(\mathrm{P}=0.469)$ and Egger's regression test $(\mathrm{P}=0.3093)$ tests. The pooled ORs remained significant after 3 more studies were added to both meta-analyses using the trim-and-fill method (Supplementary material 1b (Rahman et al., 2021b)). Sensitivity analyses were consistent for different values of study variance and heterogeneity (Supplementary material 1c (Rahman et al., 2021b)).

\section{Relationships between hypertension and nephrolithiasis}

As demonstrated in Figure 3, prior HTN (hypertension) was significantly associated with the risk of nephrolithiasis (RR: 1.613; 95\% CI, 1.213-2.169) in the meta-analysis of 14 observational studies. There was high heterogeneity $(\mathrm{Q}$ test, $\mathrm{P}<0.001$; I 2 = 98\%). Also, publication bias and small study effect were not suggested based on the symmetry of the funnel plot and the Begg's $(P=0.233)$ and Egger's $(P=0.1386)$ tests (Supplementary material 2a (Rahman et al., 2021b)). The pooled ORs remained significant after 6 more studies were added to both meta-analyses using the trim-and-fill method (Supplementary material $2 \mathrm{~b}$ (Rahman et al., 2021b)). Sensitivity analyses were consistent for different values of study variance and heterogeneity. (Supplementary material 2c (Rahman et al., 2021b)).

\section{Relationships between DM and nephrolithiasis}

The results of meta-analyses that assessed the relationship between diabetes and nephrolithiasis were shown in Figure 3. DM was significantly linked to increased risk of nephrolithiasis formation (RR: 1.552; 95\% CI, 1.027-2.344). For incident nephrolithiasis with Begg's $(\mathrm{P}=1.000)$ and Egger's $(\mathrm{P}=0.3106)$ tests revealed no publication bias however funnel plots were asymmetrical with a few dots outside the intervals (Supplementary material 3a (Rahman et al., 2021b)). There were no new studies added by the trim-and-fill method and the results of sensitivity analyses remained consistent in different values of study variances and heterogeneity (Supplementary Item $3 \mathrm{~b}$ and $3 \mathrm{c}$ (Rahman et al., 2021b)). High heterogeneity existed in the analyses of nephrolithiasis incident (Q test, $\mathrm{I}^{2}=97 \%$ )

\section{Relationship between obesity and nephrolithiasis}

The pooled analysis of OR of 10 individual studies showed that patients with obesity had overall RR to the risk of nephrolithiasis of 1.531 [95\%CI: 1.099-2.109]. Publication bias and small study effect were not found based on symmetry of the funnel plot (Supplementary material 4a (Rahman et al., 2021b)) and the results of Begg's $(\mathrm{P}=0.8618)$ and Egger's $(\mathrm{P}=0.9990)$ test. After four more studies added to meta analyses by using the trim-and-fill method, the pooled ORs remained significant (Supplementary material 4b (Rahman et al., 2021b)). Despite high heterogeneity existed (Q test, $\mathrm{I}^{2}=96 \%$ )

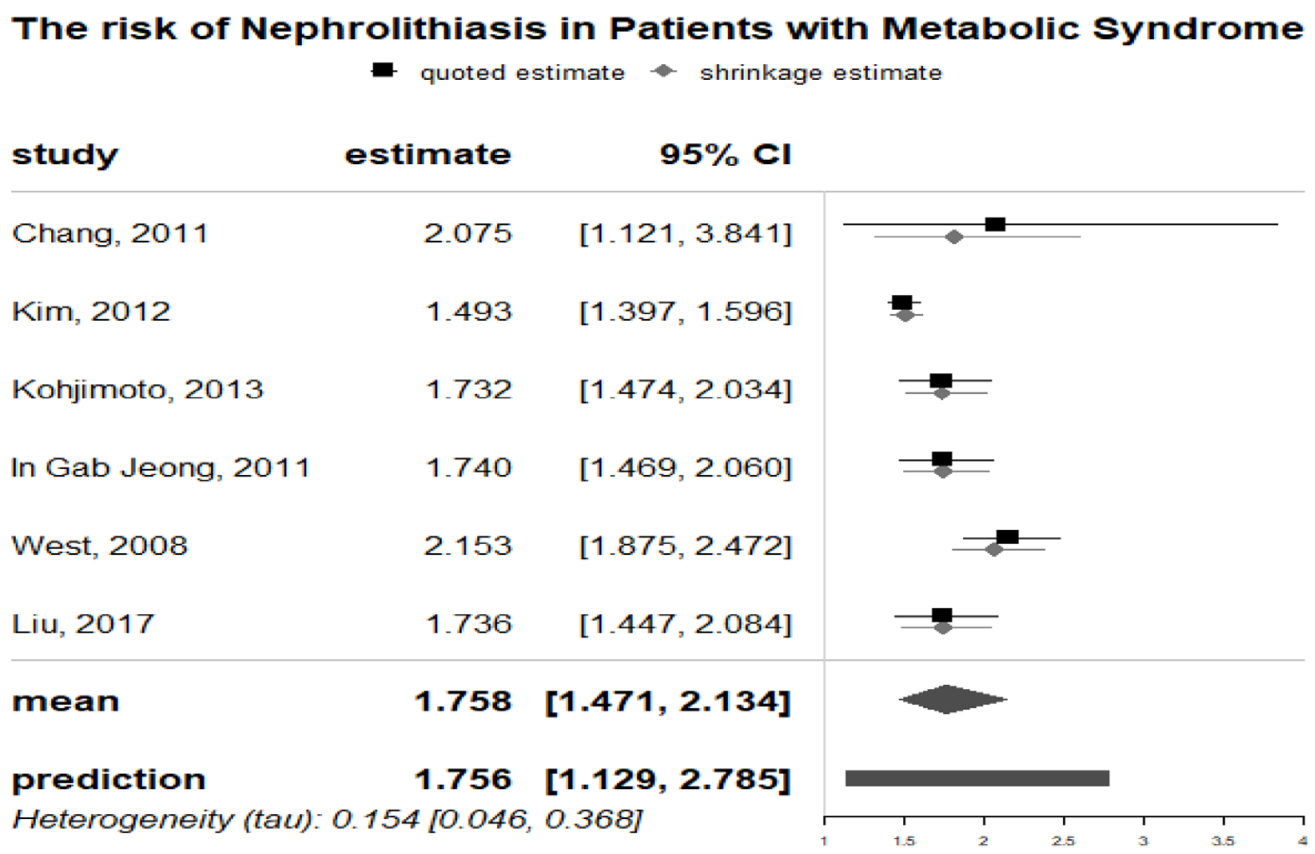

Figure 2. Forrest plot of nephrolithiasis risk in metabolic syndrome patients. 
The risk of Nephrolithiasis in Patients with Hypertension

- quoted estimate * shrinkage estimate

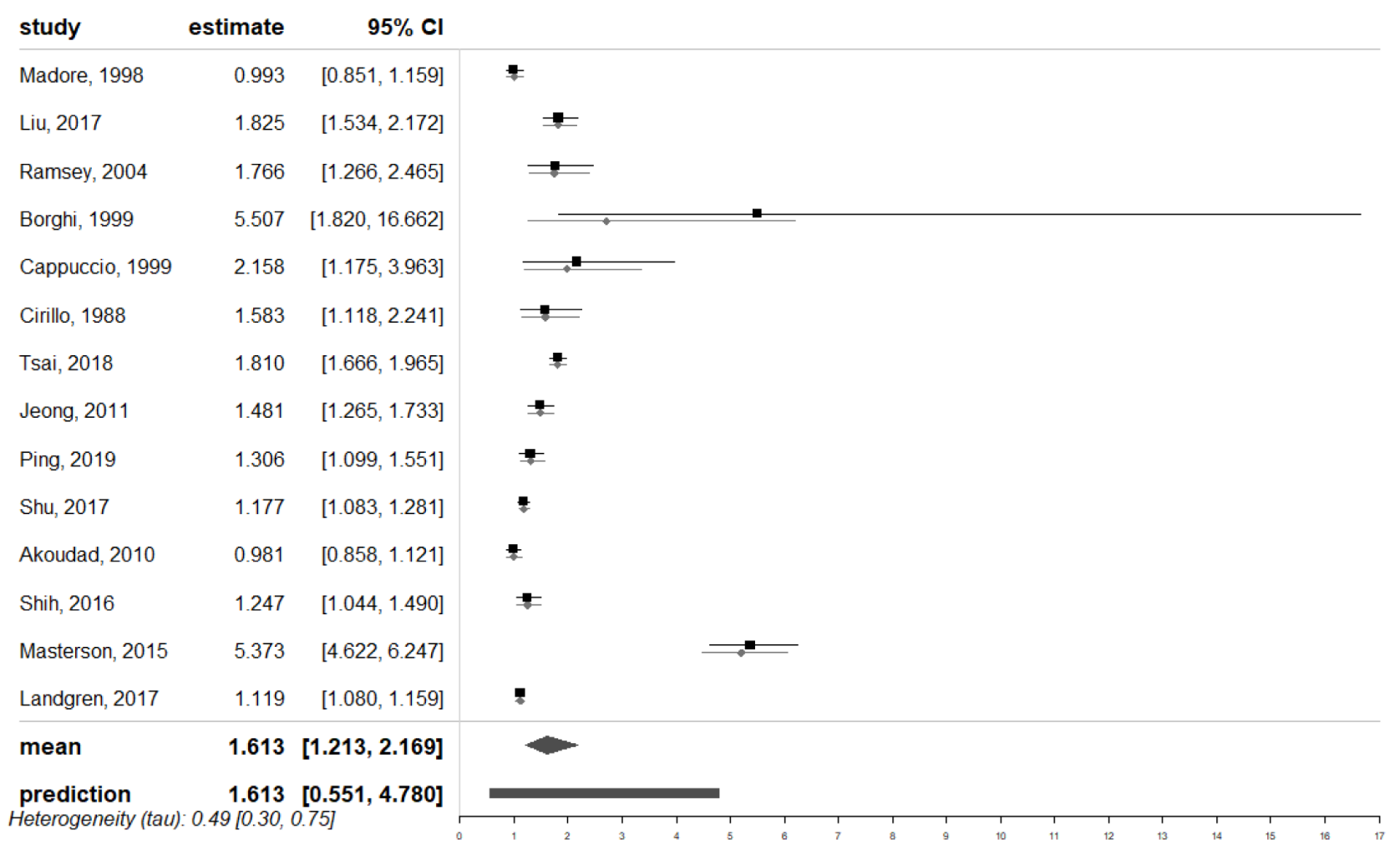

The risk of Nephrolithiasis in Patients with Diabetes Mellitus

- quoted estimate shrinkage estimate

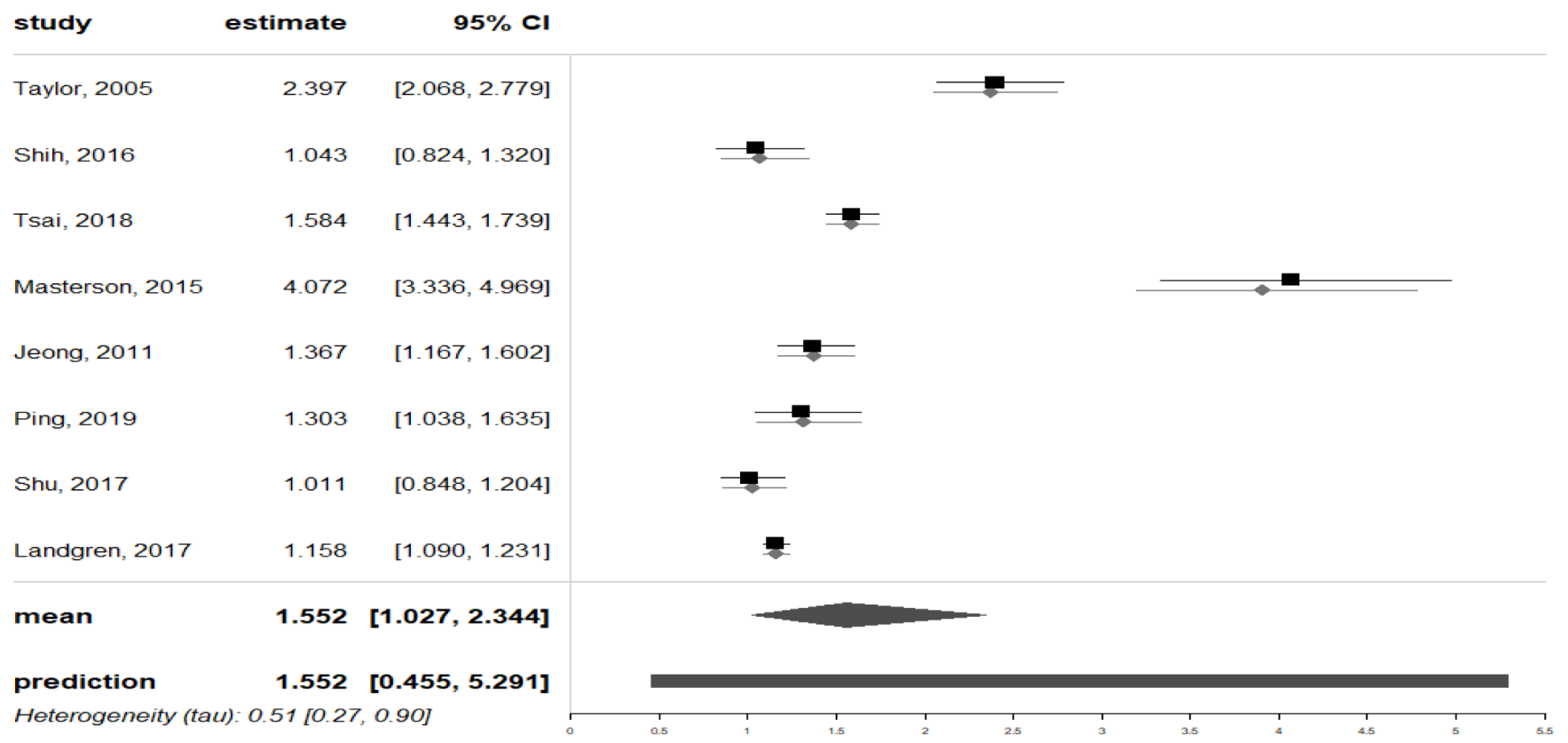




\section{The risk of Nephrolithiasis in Patients with Obesity}

- quoted estimate - shrinkage estimate

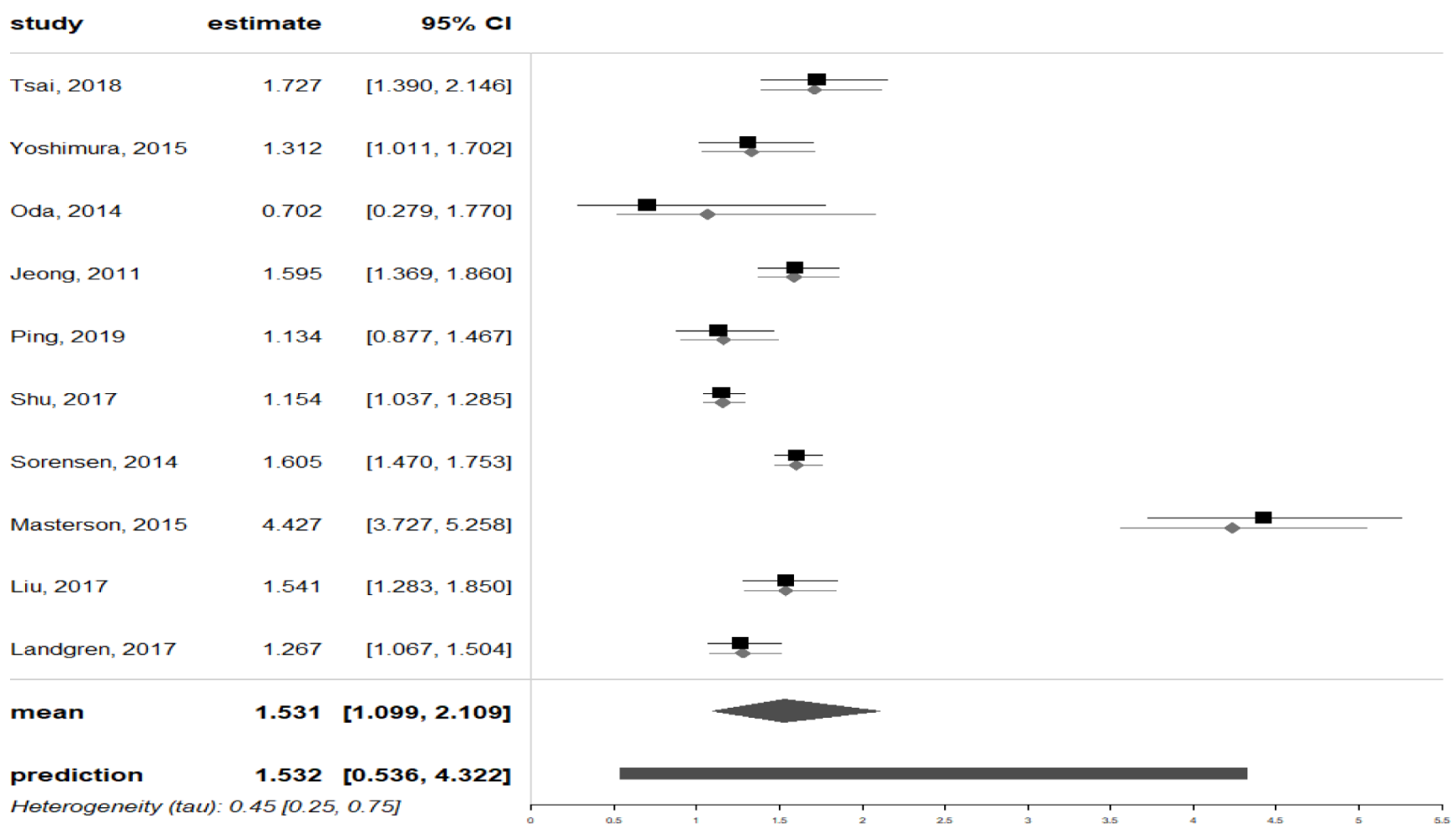

\section{The risk of Nephrolithiasis in Patients with Dyslipidemia}

- quoted estimate - shrinkage estimate

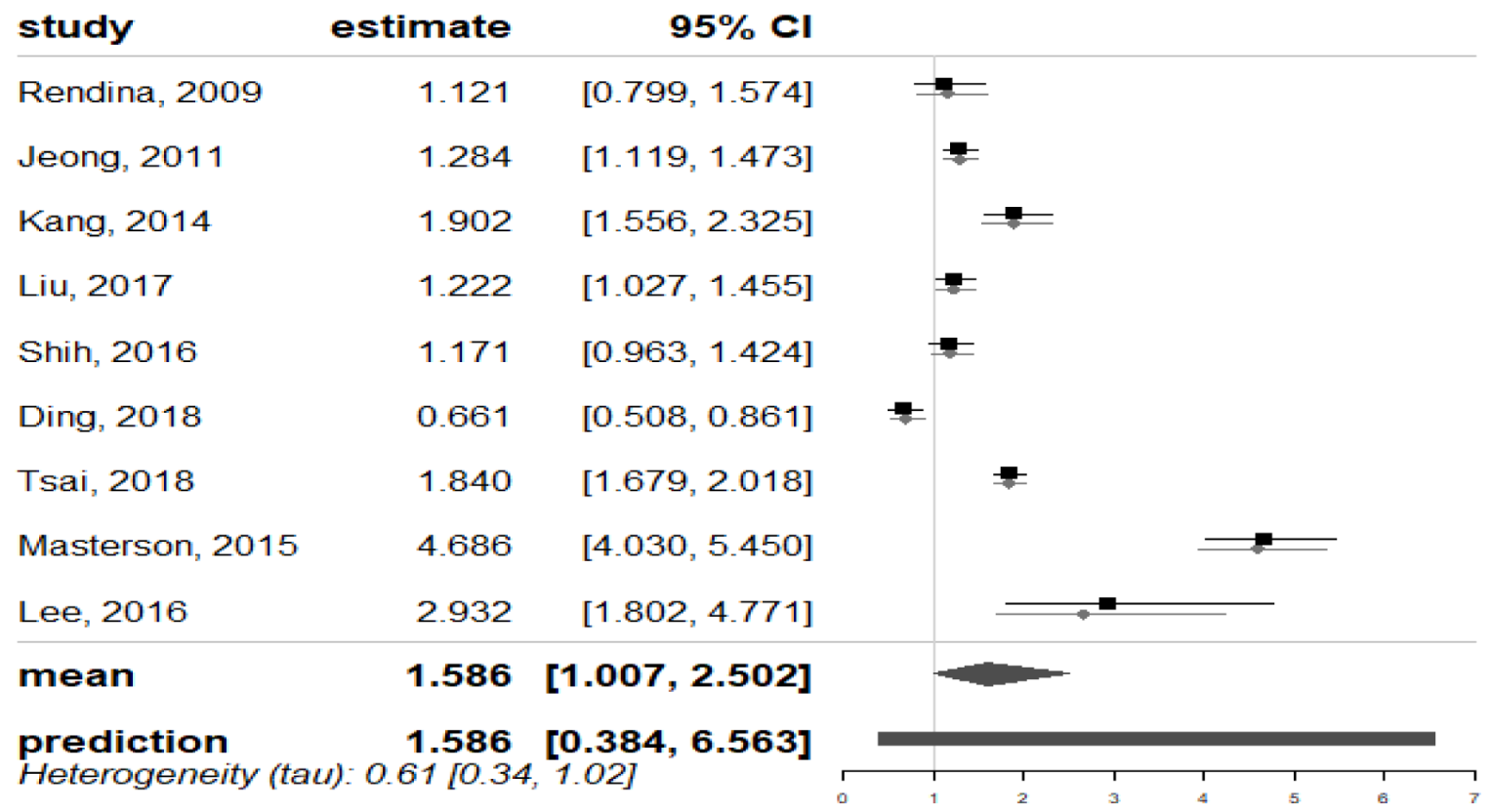

Figure 3. The association of metabolic syndrome traits and kidney stones incident using empirical Bayesian meta-analysis. 
between studies, the results of sensitivity analyses remained consistent in different values of study variances (Supplementary material 4c (Rahman et al., 2021b)).

\section{Relationships between dyslipidemia and nephrolithiasis}

There were significant associations between dyslipidemia and nephrolithiasis as demonstrated in Figure 3. Specifically, patients with dyslipidemia were 1.586 times more likely to develop nephrolithiasis (95\% CI, 1.007 -2.502). In this pooled analysis, the heterogeneity was substantial with $\mathrm{I}^{2}=97 \%$. The funnel plot of studies assessing dyslipidemia and the risk of nephrolithiasis indicated potential publication bias that was however not supported by the result of Begg's $(\mathrm{P}=0.9195)$ and Egger's $(\mathrm{P}=0.5712)$ tests (Supplementary Item 5a (Rahman et al., 2021b)). The pooled ORs remained significant after 1 new study added with the trim and fill analysis. Sensitivity analyses yielded consistent results (Supplementary Item 5b and 5c (Rahman et al., 2021b)).

\section{Meta regression and dose response analysis}

As demonstrated in Figure 4, the effect of metabolic syndrome traits on kidney stone formation was also assessed by using Bayesian meta regression in six reports on the study of MetS and nephrolithiasis. Stratification for hypertension, dyslipidemia, obesity, and diabetes were conducted. Moreover, linear dose response analysis was also conducted as shown in Figure 5. Our analyses revealed that the incident of nephrolithiasis was significantly associated ( $p$ value $<0.05$ ) with the increasing of age. Fasting plasma glucose and body mass index were also reported to significantly associated ( $\mathrm{p}$ value $<0.05$ ) with incidence of kidney stones. The more increased the fasting glucose and body mass index then the more increased the risk of kidney stones incident. Linear correlation was also found in metabolic traits where the increasing number of MetS traits will increase the risk of developing nephrolithiasis. For the effect of blood pressure, there is a trend that the more increased blood pressure then the more increased risk of kidney stones, however the result was not significant ( $\mathrm{p}$ value > 0.05). HDL (high density lipoprotein) level revealed no trend and significance ( $p$ value $>0.05$ ) for the association with kidney stone incident.

\section{Discussion}

To the best of our knowledge, this is the first systematic review study to confirm the associations between nephrolithiasis and metabolic syndrome components using Bayesian metaanalysis with meta regression and dose response analysis. All studies selected for meta-analysis were of high quality with NOS $\geq 7$. Our results indicated significant relationships between kidney stones and metabolic syndrome traits such as hypertension, diabetes, obesity, and dyslipidemia. Although heterogeneity existed across most analyses, the results were consistent in all sensitivity analyses and trim-and-fill tests, suggesting these relationships were relatively robust and unlikely to be the consequence of confounding.

Our results indicate that hypertension has been associated as a risk factor in the development of nephrolithiasis. Our result is also in coherent with (Cappuccio et al., 1990) where we found that the risk of kidney stones development was increased stepwise with the severity of hypertension that the higher the blood pressure, the higher the risk in developing nephrolithiasis. The relationship could be clarified by many possible mechanisms. Hypercalciuria or increased renal calcium excretion was identified as the first theory concerning the relation between hypertension and nephrolithiasis. This hypothesis was also supported in previous studies that HTN has increased the occurrence of kidney stones, by its association with hypercalciuria, hyperoxaluria, and hypocitraturia (Borghi et al., 1999; Coe et al., 2010). This hypothesis was strengthened by research (Coe \& Bushinsky, 1984; Pak et al., 1975; Resnick et al., 1986) showing that hypertensive and stone-forming patients often have certain hormonal correlations, such as elevated levels of $1,25(\mathrm{OH}) 2 \mathrm{D}$ and parathyroid hormone, which may justify the finding of hypercalciuria in large subgroups of both subjects. This hypothesis is linked for stones containing calcium, including calcium oxalate and calcium phosphate (Coe et al., 2010). A primary renal tubular defect (the 'renal calcium leak' hypothesis) or the result of central volume expansion observed in hypertension (the 'central blood volume' hypothesis) may be attributed to increased urinary calcium excretion. This disorder is well evident in the Italian cohort studied by Borghi et al. (Borghi et al., 1999), where urinary calcium excretion was higher in hypertensive patients, both men and women, than in normotensive patients. Previous authors also advance the hypothesis that a pathogenic relation between hypertension and nephrolithiasis may be caused by the increased renal calcium excretion (Devynck et al., 1984; McCarron, 1985; Resnick, 1987). Previous research also revealed that there is an existence of calcium metabolism alterations, including increased renal excretion both in hypertensive animals (Hsu et al., 1986; Wexler \& McMurtry, 1981) and humans (Gennari et al., 1986; Strazzullo et al., 1983). Furthermore, it is understood that these conditions are aggravated by a high dietary intake of sodium chloride. High dietary salt intake will in particular, facilitate hypertension by volume expansion and stone forming through increasing urinary calcium excretion and reducing citrate (Canessa et al., 1980; Postnov et al., 1979). This finding was also confirmed by research (Borghi et al., 1999) showing that in many hypertensive patients, the effect of $\mathrm{NaCl}$ intake appears to be important in inducing high blood pressure and causing high calcium excretion. It is well known that a small increase in urinary oxalate increases the lithogenic risk of calcium oxalate, while hyperuricosuria can encourage both uric oxalate production (Robertson \& Peacock, 1980). Genetic theory also describes how genetics is associated with calcium metabolism alterations in hypertension and kidney stone incident. A previous study (Cirillo et al., 1989) also reported that alteration in renal calcium handling in hypertensive rats led to higher urinary calcium excretion. Other epidemiological studies tend to indicate that hypertensive subjects and stone formers have common dietary patterns, distinguished above all by a low consumption of calcium (McCarron \& Morris, 1987; McCarron et al., 1984; Menon, 1993), which, as is well known, can contribute to increased oxaluria due to increased intestinal oxalate absorption. This theory is born out of the fact that the reduction of arterial pressure levels and reduction of the 

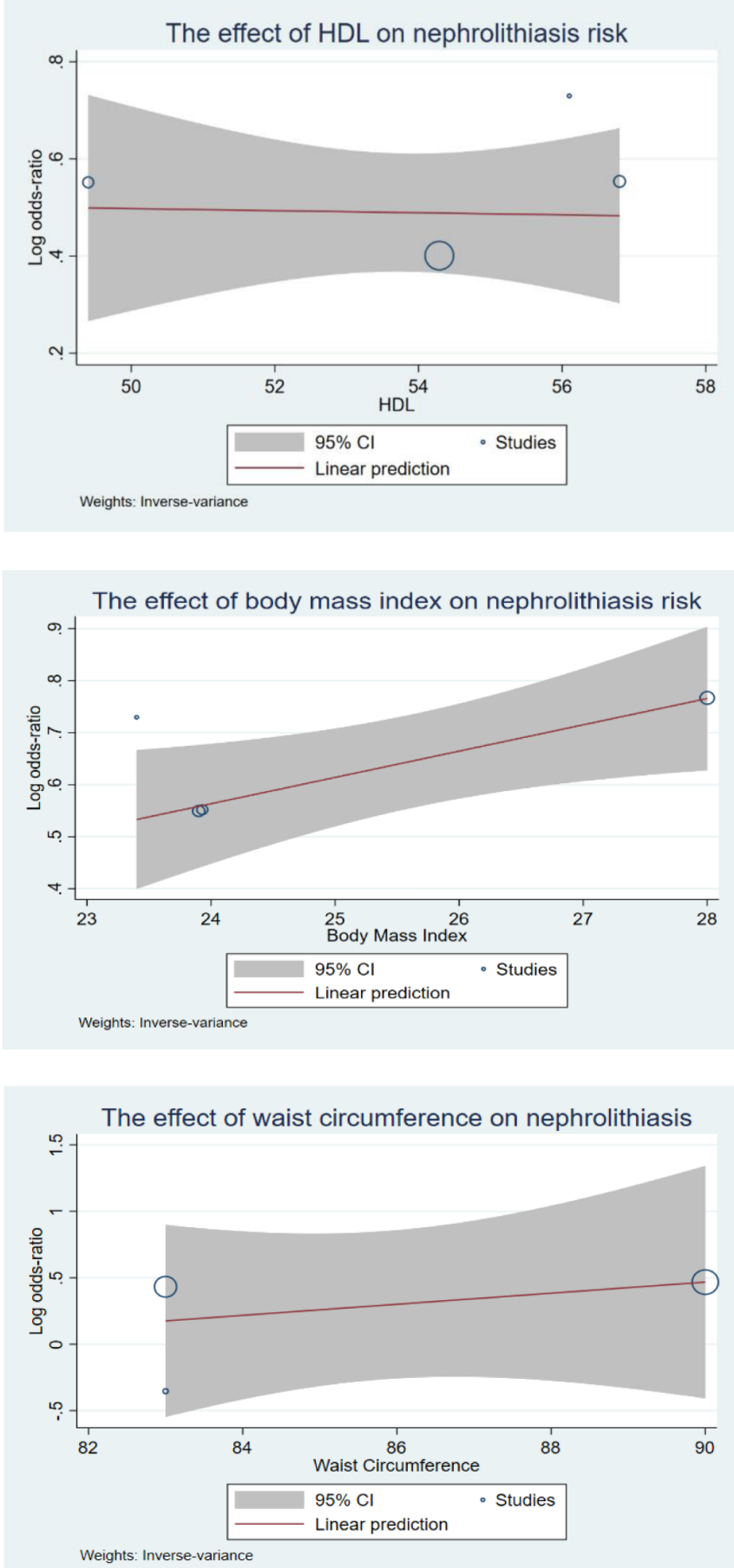
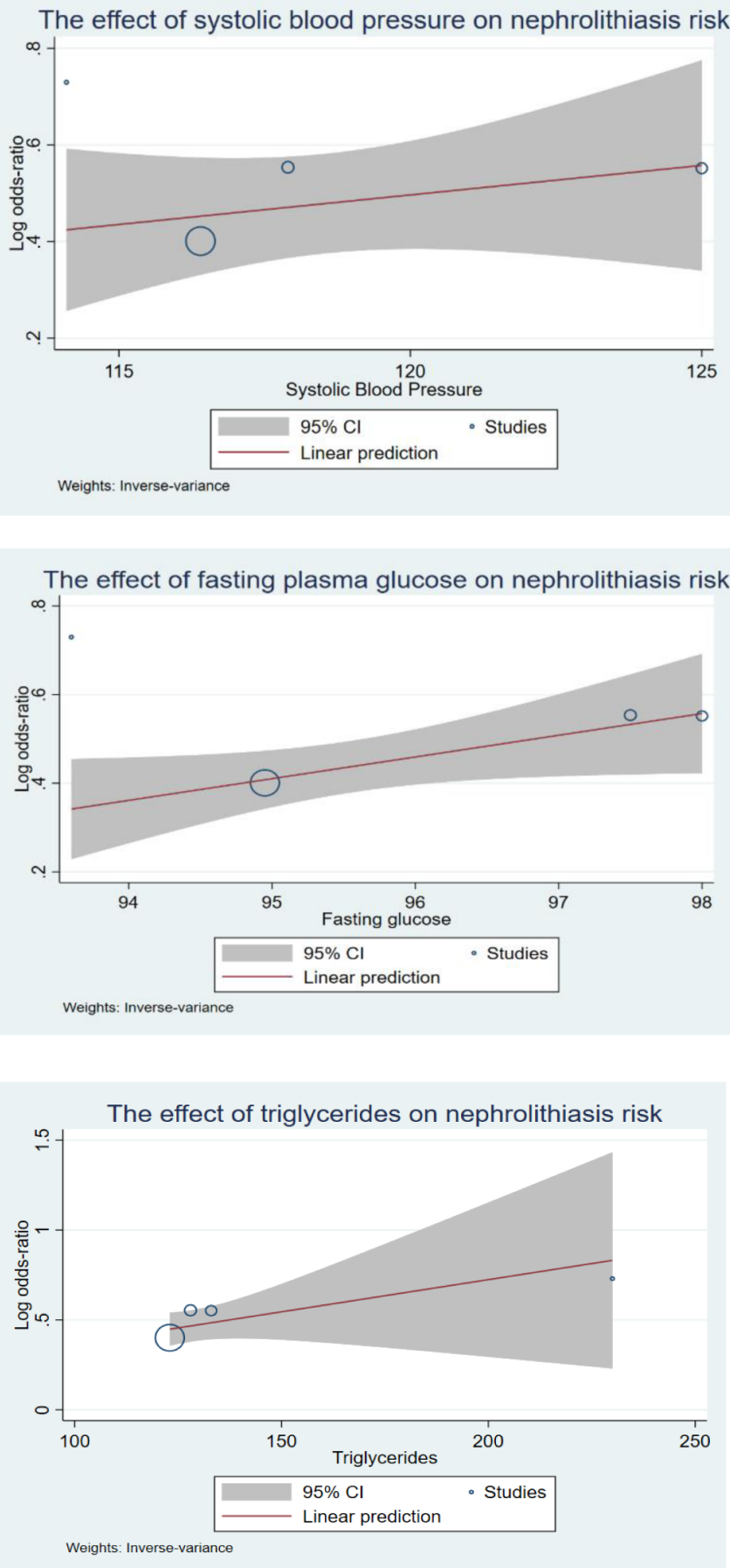

Figure 4. The association of metabolic syndrome traits and risk of kidney stones incident using Empirical Bayesian meta regression.

likelihood of renal stone development appear to be supported by calcium-rich diet (Curhan et al., 1997).

A significant association of DM with the risk of nephrolithiasis was reported in our research. It is well known that by deranging ammoniagenesis and increasing sodium and bicarbonate reabsorption, insulin resistance, as the central feature of DM, could cause decreased urine $\mathrm{pH}$ (Spatola et al., 2018). Insulin resistance causes high levels of plasma-free fatty acids to reach the proximal tubule cells and interfere with the use of glutamine 


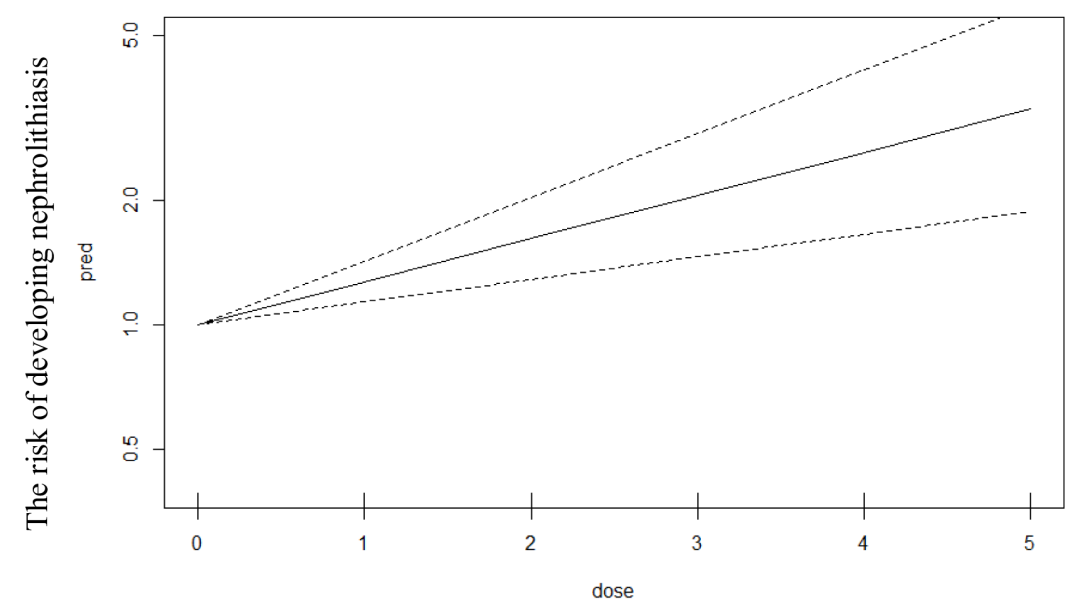

Number of metabolic syndrome traits

Figure 5. Linear model of dose response analysis between number of metabolic syndrome traits and the risk of developing nephrolithiasis.

in ammonium production (Bagnasco et al., 1983; Lemieux et al., 1977; Vinay et al., 1976). Furthermore, insulin resistance may directly affect ammoniagenesis at the level of the kidney. This could lead to lower urinary $\mathrm{PH}$ which is a major risk factor for uric acid nephrolithiasis (Asplin, 1996; Riese \& Sakhaee, 1992). However, a lower level of urinary citrate also resulted in DM, which further induced hypercalciuria due to reduced citrate binding (Spatola et al., 2018). In addition, through isonatric inhibition of proximal tubular reabsorption of calcium, hyperglycemia and concurrent glycosuria acted separately to elevate urinary calcium excretion. These pathways, working together, facilitated the development of uric acid and calcium stone in diabetic patients (Daudon et al., 2006). Our results also provide evidence that there is a trend that the risk of developing nephrolithiasis was correlated with the higher the fasting plasma glucose. The links between distinct glycemic status and kidney stone disorder have been explored in recent research. Positive correlations between prediabetes and diabetes with the risk of nephrolithiasis were seen in the results and with insulin resistance, a greater risk of kidney stones was found (Lien et al., 2016; Weinberg et al., 2014). Thus it is possible that kidney stones are developed after prediabetes, but before DM progresses. As a consequence of diagnostic chronology, this may partially explain the greater incidence of DM in kidney stone patients.

Insulin resistance may also play role in the link between obesity and nephrolithiasis which was reported in our research. In previous studies, urinary calcium excretion and body mass index (BMI) were found to be positively correlated (Ekeruo et al., 2004; Powell et al., 2000; Siener et al., 2004). It is well understood that one of the characteristics of obesity is insulin resistance. In patients with high BMI, it is found that increased uric acid excretion, low urinary $\mathrm{pH}$ both cause urinary supersaturation (Maalouf et al., 2004; Powell et al., 2000). Insulin resistance with urinary $\mathrm{pH}<5.5$ through the activation of exchanger $\mathrm{NH} 3$ in the proximal renal tubule thus reduces the synthesis and urinary excretion of ammonium (Abate et al., 2004; Chobanian \& Hammerman, 1987; Klisic et al., 2002). In acid urine, uric acid is found in an undissociated, readily precipitable state such that the deposition of uric acid stone can easily take place (Pak et al., 2001). Excess uric acid in the urine can also by a heterogeneous nucleation process, causing the precipitation of calcium oxalate dehydrate (Coe et al., 1980). The process of insulin resistance is not influenced by diet and lifestyle (Kovesdy et al., 2017).

Our study reveals that there was a 1.586 -fold increased risk of nephrolithiasis in participants with dyslipidemia. There has been previous meta-analysis that supports the correlation between dyslipidemia and nephrolithiasis (Besiroglu \& Ozbek, 2019). Our result was also supported by the fact that consuming statin medications can reduce stone genesis compared to those not consuming statin medications (Inci et al., 2012; Sur et al., 2013). The study from Toricelli et al. (Torricelli et al., 2014) also reported low HDL and high TGs (triglycerides) are associated with lower urinary $\mathrm{pH}$, and uric acid stones. Possible linking mechanism was explained that dyslipidemia and similar diseases are often concerned with systemic inflammation and oxidative stress (Gorbachinsky et al., 2010). They concluded that oxidative stress tends to be a key cytotoxic activity of the monohydrate calcium oxalate that can harm or destroy renal cells, and by unknown cellular physiological mechanisms could also contribute to stone forming. The oxidative stress cascade, which is the leading factor in cell damage, may be caused by 
dyslipidemia. Ultimately, the area of oxidatively stressed may lead to crystallization by the contribution of high calcium and phosphate or oxalate, and low urine citrate or magnesium. Moreover, lipid accumulation in the kidney which is defined as lipotoxicity caused changes in renal structure and function (Gorbachinsky et al., 2010). Lipotoxicity can induce an increased acid extraction, with decreased ammonia synthesis and ammonium excretion, resulting in a lower urinary $\mathrm{pH}$. Bobulescu et al. (Bobulescu et al., 2008) in the rats study also revealed that TG steatosis around the tubular portions of the kidney is associated with low urinary $\mathrm{pH}$ and $\mathrm{NH}_{4}{ }^{+}$and high titratable acidity. They demonstrated that the decrease in NH4+ excretion might be attributed to a lipotoxicity-induced reduction in NHE3 activity. In a follow up study of Bobulescu and colleagues, the reduction of renal steatosis in rats improved urinary $\mathrm{NH}^{+}$, increased $\mathrm{pH}$, reduced titratable acidity and finally increased citrate and brush border NHE3 levels and activity was demonstrated (Bobulescu et al., 2009).

The current findings have important public health implications in light of the current epidemics of obesity, diabetes, hypertension and dyslipidemia and suggest that these four factors play important roles in the development of nephrolithiasis. With this knowledge, determining common modifiable risk factors for the development of kidney stones might uncover new strategies enabling improved patient management and treatment of stone disease. Finally, there are several strengths of this review. First, the implementation of Bayesian framework in meta-analysis and meta regression could provide better confidence in the results; therefore, it gives clarity in the associations between nephrolithiasis and metabolic syndrome traits. Second, the results were tested using sensitivity analysis, trim-fill analysis, funnel plot, Begg's rank correlation and Egger's regression test to ensure that the results were relatively consistent and robust without the influence of confounders. Third, all studies selected for meta-analysis were of high quality, which report the association between the traits and nephrolithiasis. However, there are several limitations in this study. Firstly, the number of studies that can be pooled due to the fact that not many primary study have been conducted; secondly, not all studies included stone analysis therefore it is difficult to observe the association between metabolic syndrome components and different type of kidney stones; and thirdly, there are not many individual studies on metabolic syndrome and further updated meta-analyses need to be performed.

\section{Data availability}

Underlying data

All data underlying the results are available as part of the article and no additional source data are required.

\section{Extended data}

Dryad: Data from: Association between metabolic syndrome components and the risk of developing nephrolithiasis: Bayesian meta-analysis and meta-regression with dose-response analysis, https://doi.org/10.5061/dryad.76hdr7svg (Rahman et al., 2021b).

This project contains the following extended data:

- Supplementary material 1. Funnel plot (a), trim-fill (b) and sensitivity analysis (c) of the association between metabolic syndrome and nephrolithiasis

- Supplementary material 2. Funnel plot (a), trim-fill (b) and sensitivity analysis (c) of the association between hypertension and nephrolithiasis

- Supplementary material 3. Funnel plot (a), trim-fill (b) and sensitivity analysis (c) of the association between DM and nephrolithiasis

- Supplementary material 4. Funnel plot (a), trim-fill (b) and sensitivity analysis (c) of the association between obesity and nephrolithiasis

- Supplementary material 5. Funnel plot (a), trim-fill (b) and sensitivity analysis (c) of the association between dyslipidemia and nephrolithiasis

Data are available under the terms of the Creative Commons Zero "No rights reserved" data waiver (CC0 1.0 Public domain dedication).

\section{Reporting guidelines}

Figshare: PRISMA checklist for 'Comparison of major bleeding in patients with acute coronary syndrome that underwent coronary artery bypass grafting treated with clopidogrel or ticagrelor: a systematic review and meta-analysis, https://doi.org/ 10.6084/m9.figshare.13585607 (Rahman et al., 2021a).

Data are available under the terms of the Creative Commons Attribution 4.0 International license (CC-BY 4.0).
Abate N, Chandalia M, Cabo-Chan Jr AV, et al.: The metabolic syndrome and uric acid nephrolithiasis: Novel features of renal manifestation of insulin resistance. Kidney Int. 2004; 65(2): 386-392.

PubMed Abstract | Publisher Full Text

Asplin JR: Uric acid stones. Semin Nephrol. 1996; 16(5): 412-424. PubMed Abstract

Aune $D$, Mahamat-Saleh $Y$, Norat $T$, et al.: Body fatness, diabetes, physical activity and risk of kidney stones: a systematic review and meta-analysis of cohort studies. EurJ Epidemiol. 2018; 33(11): 1033-1047. PubMed Abstract | Publisher Full Text | Free Full Text Bagnasco SM, Gaydos DS, Risquez A, et al.: The regulation of renal ammoniagenesis in the rat by extracellular factors. III. Effects of various fuels on in vitro ammoniagenesis. Metabolism. 1983; 32(9): 900-905. PubMed Abstract | Publisher Full Text

Besiroglu H, Ozbek E: Association between blood lipid profile and urolithiasis: A systematic review and meta-analysis of observational 
studies. Int J Urol. 2019; 26(1): 7-17.

PubMed Abstract | Publisher Full Text

Bobulescu IA, Dubree M, Zhang J, et al.: Effect of renal lipid accumulation on proximal tubule $\mathrm{Na}^{+} / \mathrm{H}^{+}$exchange and ammonium secretion. Am J Physiol Renal Physiol. 2008; 294(6): F1315-22.

PubMed Abstract | Publisher Full Text | Free Full Text

Bobulescu IA, Dubree M, Zhang J, et al.: Reduction of renal triglyceride accumulation: Effects on proximal tubule $\mathrm{Na}^{+} / \mathrm{H} \pm$ exchange and urinary acidification. Am J Physiol Renal Physiol. 2009; 297(5): F1419-26.

PubMed Abstract | Publisher Full Text | Free Full Text

Borghi L, Meschi T, Guerra A, et al.: Essential arterial hypertension and stone disease. Kidney Int. 1999; 55(6): 2397-2406.

PubMed Abstract | Publisher Full Text

Canessa M, Adragna N, Solomon HS, et al.: Increased Sodium-Lithium Countertransport in Red Cells of Patients with Essential Hypertension. N EnglJ Med. 1980; 302(14): 772-776.

PubMed Abstract | Publisher Full Text

Cappuccio FP, Strazzullo P, Mancini M: Kidney stones and hypertension: Population based study of an independent clinical association. BMJ. 1990; 300(6734): 1234-1236.

PubMed Abstract | Publisher Full Text | Free Full Text

Chobanian MC, Hammerman MR: Insulin stimulates ammoniagenesis in canine renal proximal tubular segments. Am J Physiol. 1987; 253((6 Pt 2):

F1171-7.

PubMed Abstract | Publisher Full Text

Cirillo M, Galletti F, Strazzullo P, et al.: On the pathogenetic mechanism of hypercalciuria in genetically hypertensive rats of the milan strain. $A m$ J Hypertens. 1989; 2(10): 741-746.

PubMed Abstract | Publisher Full Text

Coe FL, Bushinsky DA: Pathophysiology of hypercalciuria. Am J Physiol. 1984 247(1 Pt 2): F1-13.

PubMed Abstract | Publisher Full Text

Coe FL, Evan AP, Worcester EM, et al.: Three pathways for human kidney

stone formation. Urol Res. 2010; 38(3): 147-160.

PubMed Abstract | Publisher Full Text | Free Full Text

Coe FL, Strauss AL, Tembe V et al: Uric acid saturation in calcium

nephrolithiasis. Kidney Int. 1980; 17(5): 662-668.

PubMed Abstract | Publisher Full Text

Curhan GC, Willett WC, Speizer FE, et al:: Comparison of dietary calcium with supplemental calcium and other nutrients as factors affecting the risk for kidney stones in women. Ann Intern Med. 1997; 126(7): 497-504.

PubMed Abstract | Publisher Full Text

Daudon $\mathrm{M}$, Traxer $\mathrm{O}$, Conort $\mathrm{P}$, et al.: Type 2 diabetes increases the risk for uric acid stones. J Am Soc Nephrol. 2006; 17(7): 2026-2033.

PubMed Abstract | Publisher Full Text

Devynck MA, Pernollet MG, Deray G, et al.: Investigation of the endogenous

Na+-pump inhibitor in essential hypertension and blood volume

expansion. J Hypertens Suppl. 1984; 2(3): S453-455.

PubMed Abstract

Dhondup T, Kittanamongkolchai W, Vaughan LE, et al.: Risk of ESRD and Mortality in Kidney and Bladder Stone Formers. Am J Kidney Dis. 2018; 72(6): 790-797.

PubMed Abstract | Publisher Full Text | Free Full Text

Ekeruo WO, Tan YH, Young MD, et al.: Metabolic risk factors and the impact of medical therapy on the management of nephrolithiasis in obese patients. J Urol. 2004; 172(1): 159-163.

PubMed Abstract | Publisher Full Text

Gennari C, Nami R, Bianchini C, et al.: Renal excretion of calcium in human hypertension. Am J Nephrol. 1986; 6 Suppl 1: 124-127.

PubMed Abstract | Publisher Full Text

Gorbachinsky I, Akpinar H, Assimos DG: Metabolic syndrome and urologic diseases. Rev Urol. 2010; 12(4): e157-80.

PubMed Abstract | Free Full Text

Greenland S: Quantitative methods in the review of epidemiologic

literature. Epidemiol Rev. 1987; 9: 1-30.

PubMed Abstract | Publisher Full Text

Hiatt RA, Dales LG, Friedman GD, et al.: Frequency of urolithiasis in a prepaid medical care program. Am J Epidemiol. 1982; 115(2): 255-265.

PubMed Abstract | Publisher Full Text

Higgins JPT, Thompson SG, Deeks J], et al.: Measuring inconsistency in metaanalyses. [journal article as teaching resource, deposited by John Flynn]. BMJ. 2003; 115(7414): 557-60

PubMed Abstract | Publisher Full Text | Free Full Text

Hsu CH, Chen PS, Smith DE, et al:: Pathogenesis of hypercalciuria in spontaneously hypertensive rats. Miner Electrolyte Metab. 1986; 12(2): 130-141.

PubMed Abstract

Inci $M$, Demirtas $A$, Sarli $B$, et al:: Association between body mass index, lipid profiles, and types of urinary stones. Ren Fail. 2012; 34(9): 1140-1143. PubMed Abstract | Publisher Full Text

Klisic J, Hu MC, Nief V, et al:: Insulin activates $\mathrm{Na}(+) / \mathrm{H}(+)$ exchanger 3 :
Biphasic response and glucocorticoid dependence. Am J Physiol Renal Physiol. 2002; 283(3): F532-9.

PubMed Abstract Publisher Full Text

Kovesdy CP, Furth SL, Zoccali C: Obesity and kidney disease: hidden

consequences of the epidemic. J Bras Nefrol. 2017; 39(1): 1-10.

PubMed Abstract | Publisher Full Text

Kovshilovskaya B, Chi T, Miller J, et al.: Systemic implications of urinary stone disease. Transl Androl Urol. 2012; 1(2): 89-96.

PubMed Abstract | Publisher Full Text | Free Full Text

Lemieux G, Vinay P, Gougoux A, et al.: Relationship between the rena metabolism of glutamine, fatty acids and ketone bodies. Curr Prob/ Clin Biochem. 1977: 8: 379-388.

PubMed Abstract

Lien TH, Wu JS, Yang YC, et al.: The effect of glycemic status on kidney stone disease in patients with prediabetes. Diabetes Metab J. 2016; 40(2): 161-166. PubMed Abstract | Publisher Full Text | Free Full Text

Maalouf NM, Sakhaee K, Parks JH, et al.: Association of urinary pH with body weight in nephrolithiasis. Kidney Int. 2004; 65(4): 1422-1425.

PubMed Abstract | Publisher Full Text

McCarron DA, Morris CD: The calcium deficiency hypothesis of

hypertension. Ann Intern Med. 1987; 107(6): 919-922.

PubMed Abstract | Publisher Full Text

McCarron DA: Calcium in the pathogenesis and therapy of human

hypertension. Am J Med. 1985; 78(2B): 27-34.

PubMed Abstract | Publisher Full Text

McCarron DA, Morris CD, Henry $\mathrm{HJ}$, et al: Blood pressure and nutrient intake in the United States. Nutrition Today. 1984; 19(4): 14-23.

Publisher Full Text

Menon M: A prospective study of dietary calcium and other nutrients and the risk of symptomatic kidney stones. J Urol. 1993; 150(2 Pt 1): 563-564.

PubMed Abstract

O'Hagan A: Bayesian statistics: principles and benefits. Bayesian Statistics and Quality Modelling in Agro-Food Production Chain. (Wageningen UR Frontis Series). 2004; 31-45.

Reference

Obligado SH, Goldfarb DS: The association of nephrolithiasis with hypertension and obesity: A review. Am J Hypertens. 2008; 21(3): 257-264. PubMed Abstract | Publisher Full Text

Pak CY, Kaplan R, Bone $H$, et al:: A Simple Test for the Diagnosis of Absorptive, Resorptive and Renal Hypercalciurias. N EnglJ Med. 1975; 292(10): 497-500

PubMed Abstract | Publisher Full Text

Pak CY, Sakhaee K, Peterson RD, et al.: Biochemical profile of idiopathic uric acid nephrolithiasis. Kidney Int. 2001; 60(2): 757-761.

PubMed Abstract | Publisher Full Text

Peng JP, Zheng $\mathrm{H}$ : Kidney stones may increase the risk of coronary heart disease and stroke: A PRISMA-Compliant meta-analysis. Medicine (Baltimore). (United States). 2017; 96(34): e7898.

PubMed Abstract | Publisher Full Text | Free Full Text

Postnov YV, Orlov SN, Pokudin NI: Decrease of calcium binding by the red blood cell membrane in spontaneously hypertensive rats and in essential hypertension. Pflugers Arch. 1979; 379(2): 191-195.

PubMed Abstract | Publisher Full Text

Powell CR, Stoller ML, Schwartz BF, et al.: Impact of body weight on urinary electrolytes in urinary stone formers. Urology. 2000; 55(6): 825-830. PubMed Abstract | Publisher Full Text

Rahman IA, Nusaly IF, Syahrir S, et al.: PRISMA 2009 checklist.doc. figshare.

Figure. 2021a.

http://www.doi.org/10.6084/m9.figshare.13585607

Rahman IA, Nusaly IF, Syahrir S, et al.: Data from: Association between metabolic syndrome components and the risk of developing nephrolithiasis: Bayesian meta-analysis and meta-regression with doseresponse analysis, Dryad. 2021b.

http://www.doi.org/10.5061/dryad.76hdr7svg

Reiner AP, Kahn A, Eisner BH, et al.: Kidney stones and subclinical atherosclerosis in young adults: The CARDIA study. J Urol. 2011; 185(3):

920-925.

PubMed Abstract | Publisher Full Text | Free Full Text

Resnick LM, Müller FB, Laragh JH: Calcium-regulating hormones in essentia hypertension. Relation to plasma renin activity and sodium metabolism. Ann Intern Med. 1986; 105(5): 649-654.

PubMed Abstract | Publisher Full Text

Resnick LM: Uniformity and diversity of calcium metabolism in

hypertension. A conceptual framework. Am J Med. 1987; 82(1B): 16-26. PubMed Abstract | Publisher Full Text

Riese RJ, Sakhaee K: Uric acid nephrolithiasis: Pathogenesis and treatment. JUrol. 1992; 148(3): 765-771.

PubMed Abstract | Publisher Full Text

Robertson WG, Peacock M: The cause of idiopathic calcium stone disease: Hypercalciuria or hyperoxaluria? Nephron. 1980; 26(3): 105-110.

PubMed Abstract | Publisher Full Text 
Sakhaee K: Nephrolithiasis as a systemic disorder. Curr Opin Nephrol Hypertens. 2008; 17(3): 304-309.

PubMed Abstract | Publisher Full Text

Sakhaee K: Recent advances in the pathophysiology of nephrolithiasis. Kidney Int. 2009; 75(6): 585-595.

PubMed Abstract | Publisher Full Text | Free Full Text

Sakhaee K, Maalouf NM: Metabolic Syndrome and Uric Acid Nephrolithiasis. Semin Nephrol. 2008; 28(2): 174-180.

PubMed Abstract | Publisher Full Text

Shang W, Li Y, Ren Y, et al.: Nephrolithiasis and risk of hypertension:

A meta-analysis of observational studies. BMC Nephrol. 2017; 18(1): 344.

PubMed Abstract | Publisher Full Text | Free Full Text

Shoag J, Tasian GE, Goldfarb DS, et al.: The New Epidemiology of

Nephrolithiasis. Adv Chronic Kidney Dis. 2015; 22(4): 273-278.

PubMed Abstract | Publisher Full Text

Siener R, Glatz S, Nicolay C, et al:: The role of overweight and obesity in

calcium oxalate stone formation. Obes Res. 2004; 12(1): 106-113.

PubMed Abstract | Publisher Full Text

Spatola L, Ferraro PM, Gambaro G, et al:: Metabolic syndrome and uric acid nephrolithiasis: insulin resistance in focus. Metabolism. 2018; 83 :

225-233.

PubMed Abstract | Publisher Full Text

Spiegelhalter DJ: Incorporating Bayesian ideas into health-care evaluation.

Statist Sci. 2004; 19(1): 156-174.

Publisher Full Text

Strazzullo $\mathrm{P}$, Nunziata $\mathrm{V}$, Cirillo M, et al.: Abnormalities of calcium metabolism in essential hypertension. Clin Sci (Lond). 1983; 65(2): 137-141.

PubMed Abstract | Publisher Full Text

Sur RL, Masterson JH, Palazzi KL, et al.: Impact of statins on nephrolithiasis in hyperlipidemic patients: A 10-year review of an equal access health care system. Clin Nephrol. 2013; 79(5): 351-355.

PubMed Abstract | Publisher Full Text

Torricelli FCM, De SK, Gebreselassie $S$, et al.: Dyslipidemia and kidney stone risk. J Urol. 2014; 191(3): 667-672.

PubMed Abstract | Publisher Full Text

van de Pol JAA, van den Brandt PA, Schouten LI: Kidney stones and the risk of renal cell carcinoma and upper tract urothelial carcinoma: the Netherlands Cohort Study. Br J Cancer. 2019; 120(3): 368-374.

PubMed Abstract | Publisher Full Text | Free Full Text

Vinay $P$, Lemieux $G$, Cartier $P$, et al.: Effect of fatty acids on renal ammoniagenesis in in vivo and in vitro studies. Am J Physiol. 1976; 231(3): 880-887.

PubMed Abstract | Publisher Full Text

Weinberg AE, Patel CJ, Chertow GM, et al.: Diabetic severity and risk of kidney stone disease. Eur Urol. 2014; 65(1): 242-247.

PubMed Abstract | Publisher Full Text | Free Full Text

West B, Luke A, Durazo-Arvizu RA, et al:: Metabolic Syndrome and Self-

Reported History of Kidney Stones: The National Health and Nutrition Examination Survey (NHANES III) 1988-1994. Am J Kidney Dis. 2008; 51(5): 741-747.

PubMed Abstract | Publisher Full Text

Wexler BC, McMurtry JP: Kidney and bladder calculi in spontaneously hypertensive rats. BrJ Exp Pathol. 1981; 62(4): 369-374.

PubMed Abstract | Free Full Text 


\section{Open Peer Review}

\section{Current Peer Review Status:}

\section{Version 1}

Reviewer Report 08 November 2021

https://doi.org/10.5256/f1000research.31355.r96149

(C) 2021 Faruk M. This is an open access peer review report distributed under the terms of the Creative Commons Attribution License, which permits unrestricted use, distribution, and reproduction in any medium, provided the original work is properly cited.

\section{Muhammad Faruk}

Department of Surgery, Faculty of Medicine, Hasanuddin University, Makassar, Indonesia

This study assessed the association between metabolic syndrome and its components with the risk of developing nephrolithiasis by conducting systematic review, Bayesian random-effects meta-analysis, meta-regression and dose-response analysis. This study was done appropriately based on PRISMA flowchart. Risk of bias was also conducted of the included studies. This study has successfully presented the proper meta-analysis for this design. However, to complete this study for indexing, I personally recommended several revisions:

\section{Abstract:}

Introduction section: It is better to address meta-regression as the analysis to assess the correlation of association along with dose-response analysis

- Conclusion section: In reporting the association between predictors and nephrolithiasis, state only the predictors in which its coefficient was statistically significant

2. $\mathrm{R}$ language was not considered as a statistical software for data analysis. The software for data analysis should be written as "R" (Please refer to methods section in statistical analysis subsection).

3. Please update the PRISMA flowchart (refer to PRISMA guideline 2009).

4. Give the numbering of each Forrest plot in Figure 3 and numbering of each meta-regression plot in Figure 4. Design these figures so that it could be well presented.

5. Uniformly decide the word choice of "traits" or "components", choose whether to use traits or components in the whole text, use one of these words consistently to avoid any misunderstanding.

6. It is better to provide the meta-regression of hypertension in systolic blood pressure and diastolic blood pressure as it is important to explain the relationship to nephrolithiasis in differentiation for these two types of blood pressure. 
7. Meta-regression of body mass index was sufficient in this study thus waist circumference metaregression was not necessary to be included.

8. Provide the value of coefficient and confidence interval of each meta-regression analysis in the result section so that better understanding of predictors-outcome relationship could be reached clearly.

Are the rationale for, and objectives of, the Systematic Review clearly stated?

Yes

Are sufficient details of the methods and analysis provided to allow replication by others? Yes

Is the statistical analysis and its interpretation appropriate?

Yes

Are the conclusions drawn adequately supported by the results presented in the review? Yes

Competing Interests: No competing interests were disclosed.

Reviewer Expertise: General Surgery, Urology

I confirm that I have read this submission and believe that I have an appropriate level of expertise to confirm that it is of an acceptable scientific standard.

Reviewer Report 22 March 2021

https://doi.org/10.5256/f1000research.31355.r80876

(c) 2021 philipraj J et al. This is an open access peer review report distributed under the terms of the Creative Commons Attribution License, which permits unrestricted use, distribution, and reproduction in any medium, provided the original work is properly cited.

Joseph philipraj

Mahatma Gandhi Medical College and Research Institute, Pillayarkuppam, Puducherry, India Vishnuvardhan Rudravaram

Pondicherry university, Kalapet, Puducherry, India

This systematic review is appropriate for the journal with a global problem of Mets and Urolithiasis. The introduction part clearly explains the motivation. The manuscript is clear and balanced. The manuscript stays focused on the subject. Authors have gone through the process of searching relevant articles from all websites and of sufficient duration. The inclusion and exclusion criteria in the analysis have been clearly stated. The impact of the analysis is clearly stated. 
The statistical analysis supports the paper well. The interpretation of the results, visualisation are well presented. The tables and figures are clear, relevant and correct.

The authors demonstrate the knowledge of basic composition skills, including word choice, sentence structure, paragraph development and grammar.

\section{Limitations:}

The studies included in the meta-analysis have cross-sectional nature and hence ascertainment of temporal association is not possible which also dictates need for further prospective studies. The specific type of stone formation is not correlated with studies. Despite these limitations all studies included in the meta-analysis showed the same directionality in the association between urolithiasis and Mets.

Are the rationale for, and objectives of, the Systematic Review clearly stated? Yes

Are sufficient details of the methods and analysis provided to allow replication by others? Yes

Is the statistical analysis and its interpretation appropriate?

Yes

Are the conclusions drawn adequately supported by the results presented in the review? Yes

Competing Interests: No competing interests were disclosed.

Reviewer Expertise: Endourogy, Urolithiasis, Andrology and Male Infertility, Uro-Oncology

We confirm that we have read this submission and believe that we have an appropriate level of expertise to confirm that it is of an acceptable scientific standard. 
The benefits of publishing with F1000Research:

- Your article is published within days, with no editorial bias

- You can publish traditional articles, null/negative results, case reports, data notes and more

- The peer review process is transparent and collaborative

- Your article is indexed in PubMed after passing peer review

- Dedicated customer support at every stage

For pre-submission enquiries, contact research@f1000.com 